\title{
INDEKS SUBJECT
}

\section{A}

air tetes 136, 137, 139

Andre Tanama 110, 112, 113, 114, 118

Ari Sihasale 93

Ariswan Adhitama 110, 112, 114

Arnold Hauser 101

\section{B}

Bedhaya 27, 29, 30, 31, 33, 34, 35, 37, 42

C

cetak dalam (intaglio) 111

cetak datar 111

cetak saring (serigrafi) 111

cetak tinggi (relief) 111

\section{D}

denias 91, 92, 93, 94, 95, 96, 97

deretan titik-titik 137, 138

\section{$\mathbf{F}$}

film 91, 92, 93, 94, 95, 96, 97

filosofi Jawa garis 135

\section{G}

gaya batuan 80,82

\section{H}

Haryadi Suadi 99, 102, 108

\section{I}

I Wayan Sudiarta 99, 102, 106, 107, 108 instrumen 27, 28, 29, 30, 31, 33, 34, 35, 36, $37,34,40,41,42,45,46,47,48,55,71$ iringan gendhing mars 29 iringan tari 27, 28, 29, 30, 34, 35, 42

Irwanto Lentho $110,112,114,115$

$\mathbf{K}$

Kandjèng Kyai Guntursari 29

kapang-kapang 272934353742

karya klasik 101

karya seni lukis kontemporer 99,102, 108

karya tradisi 101 kebudayaan Bali 58

Keraton Ngayogyakarta Hadiningrat 136, 137

Keraton Yogyakarta 135, 136, 138, 140, 142, 143,147

komunitas terbayang 91, 95, 97

kubus 137, 138

kultur visual 100, 101

L

lukisan tradisonal Bali 81,82

$\mathbf{M}$

manunggaling kawulo lan Gusti 135, 136, 137, $142,144,145,146,147$

masyarakat Yogyakarta 135, 137

Mathias Muchus 93

medium seni $100,103,106$

monoprint 110, 111, 112, 113, 114, 115, 116, $117,118,119$

$\mathbf{N}$

nasionalisme 91, 92, 94, 96, 97

$\mathbf{P}$

panah-panah vertikal 137,140

Papua 91, 92, 93, 94, 95, 96, 97

pegrafis $110,111,112,114,115,116,117$, 118, 119

pegrafis Yogyakarta 110

perubahan budaya 92, 135

prisma segi delapan 137,141

proses kreatif $110,116,118,119,60,58,59$, $60,61,62,64,72$

$\mathbf{R}$

Rudolf Bonnet 78, 80

$S$

segi delapan 128, 137, 139, 141

segi empat $127,128,135,137,138$

sejarah seni $100,101,102,124$,

seni grafis 102103105110111112113114

115116117118119

seni grafis kontemporer 110 
seni lukis Bali 79, 80

seni lukis modern 106

seni lukis tradisi Bali 102,107

seni lukis tradisional 106

seni rupa 99, 100, 101, 102, 103, 105, 107, $108,110,111,112,115,117,118,119$, $110,146,147$

seni rupa Barat 101

seni rupa kontemporer 100, 101, 108, 110, 115

seni rupa modern 105

sosiologi seni 100, 101, 102

Srimpi 27, 29, 30, 33, 34, 35, 37, 42

sudut runcing 137

sudut segi enam 137

$\mathbf{T}$

T.A. Sitompul 110, 112, 113

teknik cetak 111, 113, 116

trap tiga berundak 137
Tugu Golong-Gilig $136,137,142,143,146$, 147

Tugu Yogyakarta 135, 136, 137, 142, 147

U

untiran 136, 137, 140, 147

upacara protokoler $27,28,29,30,31,32,33$, 34,35

V

visual tradisi 99, 101, 102, 106

W

wajikan 137,138

Walter Spies $35,36,42,78,80,81,82$

warna $3,4,5,6,11,23,48,49,63,64,65,66$, $68,69,71,72,81,82,106,108,113$, $114,115,116,119,122,125,127,128$, $129,130,135,136,137,141,142,143$ 